\title{
Analisis Tingkat Manajemen Stres Siswa pada Masa Pandemi Covid- 19 Implimetasi Layanan Bimbingan Konseling
}

\author{
Zakiatun Nufuus ${ }^{1 *}$, Yeni Karneli ${ }^{2}$ \\ ${ }^{1}$ Program Pendidikan Profesi Konselor (PPPK), UNP, Indonesia. \\ ${ }^{2}$ Universitas Negeri Padang, Indonesia. \\ *akianufuns@gmail.com
}

\begin{abstract}
The Covid-19 pandemic is the first and foremost health crisis in the world. A number of countries decided to close schools and colleges. The closure of various agencies in order to minimize the spread rate of Covid-19. Students who should receive direct learning, but must adapt to the LFH (learn from home) method. This condition creates a sense of stress in students. So the researchers are interested in conducting research on stress management for students of SMP Negeri 132 Jakarta during the Covid-19 pandemic. This is to find an overview of how students' stress management is, especially in this pandemic condition, which has more challenges than pre-pandemic conditions. This study aims to determine and describe the level of stress management of students at SMP Negeri 132 Jakarta during the Covid-19 pandemic. The research method used is descriptive quantitative. The sample used was 100 students who were selected using purposive sampling technique. This study uses a stress management scale based on the aspects of time management, building an optimistic attitude, managing activities wisely, avoiding procrastination, and maintaining harmonious communication. In the validity test using the product moment, there are 60 valid items with a reliability level of 0.948 in the very high category. The data analysis technique in this study used a categorization formula based on a normal distribution. The stress management of SMP Negeri 132 Jakarta as a whole is in the medium category with a total of 36 students, or $72 \%$. Furthermore, for the high category there were 8 students or $16 \%$. And the low category only amounted to 6 students or $12 \%$. While the overall level of stress management is in the medium category with 34 students or $68 \%$. Furthermore, for the high category there were 9 students or $18 \%$. And the low category only amounted to 7 students or $14 \%$. Therefore, guidance and counseling teachers can use the results of research to serve as guidelines for service delivery, so that students of SMP Negeri 132 Jakarta can reduce stress levels during the Covid-19 pandemic.
\end{abstract}

\section{Abstrak}

Pandemi Covid-19 merupakan krisis kesehatan yang pertama dan menjadi terutama di dunia. Sejumlah negara memutuskan untuk menutup sekolah dan perguruan tinggi. Ditutupnya berbagai instansi
Article Information:

Received February 2, 2021

Revised Maret 5, 2021

Accepted March 10, 2021

Keywords: stress management, pandemic period, implementation of counseling guidance services

Kata Kunci : manajemen stres, masa pandemi, implementasi layanan bimbingan konseling

How to cite: Nufuus, Z., \& Karneli, Y. (2021). Analisis Tingkat Manajemen Stres Siswa pada Masa Pandemi Covid- 19 Implimetasi Layanan Bimbingan Konseling. Prophetic Guidance and Counseling Journal, 2(1). doi: 10.32832/progcj.v2i1.4751

E-ISSN: 2614-1566

Published by: LPPM Universitas Ibn Khaldun Bogor \& Program Studi BKPI UIKA 
guna meminimalisir tingkat penyebaran Covid-19. Siswa yang seharusnya memperoleh pembelajaran secara langsung, namun harus beradaptasi dengan metode LFH (learn from home). Kondisi ini menimbulkan rasa stres dalam diri siswa. maka peneliti tertarik untuk melakukan penelitian mengenai manajemen stres siswa SMP Negeri 132 Jakarta di masa pandemi Covid-19. Hal ini untuk mengetahui gambaran bagaimana manajemen stres siswa terutama dalam kondisi pandemi ini, yang memiliki tantangan lebih dibanding kondisi pra pandemi. Penelitian ini bertujuan untuk mengetahui serta mendeskripsikan tingkat manajemen stres siswa SMP Negeri 132 Jakarta di masa pandemi Covid-19. Metode penelitian yang digunakan adalah deskriptif kuantitatif. Sampel yang digunakan berjumlah 100 siswa yang dipilih menggunakan teknik purposive sampling. Penelitian ini menggunakan skala Manajemen Stres berdasarkan aspek Manajemen waktu, Membangun Sikap Optimis, Mengatur Aktivitas Secara Bijak, Menghindari Kebiasaan Menunda, serta Menjalin Komunikasi yang harmonis. Pada uji validitas dengan menggunakan product moment terdapat 60 item valid dengan tingkar reabilitas 0,948 pada kategori sangat tinggi. Teknik analisis data pada penelitian ini menggunakan rumus kategorisasi berdasarkan distribusi normal. Manajemen stres SMP Negeri 132 Jakarta secara keseluruhan berada pada kategori sedang dengan jumlah 36 siswa, atau $72 \%$. Selanjutnya untuk kategori tinggi terdapat 8 siswa atau 16\%. Dan kategori rendah hanya berjumlah 6 siswa atau 12\%. Sedangkan tingkat manajemen stres secara keseluruhan berada pada kategori sedang dengan jumlah 34 siswa atau 68\%. Selanjutnya untuk kategori tinggi terdapat 9 siswa atau 18\%. Dan kategori rendah hanya berjumlah 7 siswa atau 14\%. Oleh karena itu guru BK dapat memanfaatkan hasil penelitian untuk dijadikan pedoman pemberian layanan, supaya siswa SMP Negeri 132 Jakarta dalam menurunkan tingkat stress di masa pandemi Covid-19.

\section{Pendahuluan}

Pandemi Covid-19 merupakan krisis kesehatan yang pertama dan menjadi terutama di dunia. Sejumlah negara memutuskan untuk menutup sekolah dan perguruan tinggi. Ditutupnya berbagai instansi guna meminimalisir tingkat penyebaran Covid-19. Berdasarkan laporan ABC News 7 Maret 2020, penutupan sekolah terjadi di lebih dari puluhan negara karena wabah Covid-19. Menurut data Organisasi Pendidikan, Keilmuan, dan Kebudayaan PBB (UNESCO), setidaknya ada 290,5 juta siswa di seluruh dunia yang aktivitas belajarnya menjadi terganggu akibat sekolah yang ditutup (Purwanto et al., 2020). Metode LFH (Learning From Home) dilakukan oleh setiap lembaga pendidikan baik sekolah maupun universitas. Tidak jarang sejumlah siswa mengalami persoalan ketika proses belajar berlangsung. Keterlambatan koneksi internet menjadi persoalan paling utama dalam proses LFH. Menurut (Syah, 2020) banyak varians masalah yang menghambat terlaksananya efektivitas pembelajaran dengan menggunakan metode daring atau Online diantaranya: Keterbatasan penguasaan teknologi informasi oleh Guru dan siswa, sarana dan prasarana yang kurang memadai, dan akses internet yang terbatas.

Akibat dari dampak pandemi, banyak persoalan yang dihadapi siswa seperti sekolah Online, keterbatasan koneksi internet, dukungan orang tua, keluarga, teman, dan lingkungan tempat tinggal yang kurang mendukung juga dapat menyebabkan berkurangnya motivasi yang dapat menghambat proses belajar dan berpikir siswa. Masalah- masalah tersebut berpengaruh pada kondisi psikis siswa, seperti mudah mengalami stres, cemas, dan 
gelisah yang selanjutnya berdampak pada kondisi fisik seperti kelelahan, pusing, lesu dan akhirnya mempengaruhi tingkat konsentrasi.

Penelitian yang dilakukan oleh Cia Guyana, Witarsa, Achmadi. Program Studi P. Ekonomi FKIP UNTAN, Pontianak dengan judul Pengaruh Manajemen Stres Terhadap Hasil Belajar Siswa Dalam Pembelajaran Akuntansi SMK Negeri 1 Pontianak, menunjukkan bahwa hasil uji persentase pada sub masalah pertama yaitu manajemen stres dalam pembelajaran akuntansi di kelas XI AK berpengaruh terhadap hasil belajar dengan hasil sebesar 74,42\% dengan kategori baik, sedangkan uji persentase pada sub masalah kedua hasil belajar siswa dalam pembelajaran akuntansi di kelas XI AK sebesar 79,76\%, dengan kategori baik. Hasil uji normalitas data pada variabel manajemen stres 0,521 dan hasil uji normalitas data pada variabel hasil belajar sebesar 0,631, yang berarti kedua variabel terdistribusi normal. Terdapat pengaruh yang signifikan dan positif manajemen stres terhadap hasil belajar siswa yang ditunjukkan dari tabel resume SPSS sebesar 0,000 dimana sig $<$ dari 0,050, dan besar pengaruh koefisien determinasi $\left(\mathrm{R}^{2}\right)$ sebesar 80\%. Dapat dipahami bahwa ketidakmampuan individu dalam memanajemen stres dapat berpengaruh kepada prokatinasi yakni menunda-nunda pekerjaan, sehingga berpengaruh ketidakcapaian tujuan yang diharapkan.

Peneliti juga melakukan studi pendahuluan melalui wawancara dengan guru BK, kepala sekolah dan beberapa siswa yang datang ke sekolah pada bulan September. Diperoleh hasil bahwa siswa mengeluhkan kondisi pandemi Covid-19 ini, karena metode LFH dirasa tidak optimal. Hambatan koneksi internet, kejenuhan siswa karena tidak bisa sekolah seperti biasa, siswa yang stres karena harus terus berada di rumah, kurangnya biaya dan fasilitas seperti harus terus membeli kuota, mempunyai smartphone agar bisa mengikuti pembelajaran Online. Tidak dapat dipungkiri kondisi pandemi Covid-19 ini memberikan pengaruh terhadap kehidupan. Siswa yang seharusnya memperoleh pembelajaran secara langsung, namun harus beradaptasi dengan metode LFH. Dan kondisi tersebut menimbulkan rasa stres dalam diri siswa.

Menurut (Waluyo, 2013, p. 91) stres merupakan suatu keadaan yang bersifat internal, yang bisa disebabkan oleh tuntutan fisik (badan), atau lingkungan, dan situasi sosial, yang berpotensi merusak dan tidak terkontrol. Sedangkan menurut (Rasmun, 2004, p. 9) stres adalah respons tubuh yang tidak spesifik terhadap setiap kebutuhan tubuh yang terganggu, suatu fenomena universal yang terjadi dalam kehidupan sehari-hari dan tidak dapat dihindari, setiap orang mengalaminya, dan berdampak pada fisik, psikologis, intelektual, sosial, dan spiritual.

Dapat disimpulkan bahwa stres merupakan suatu kondisi dimana individu mengalami tekanan yang berasal dari dalam maupun dari luar yang dipengaruhi oleh berbagai faktor, sehingga adanya penolakan atau ketidaksiapan dari diri individu. Kondisi seperti ini harus segera diatasi atau dicegah secara efektif agar tidak berkepanjangan. Oleh karena itu, diperlukan cara untuk dapat mengelola rasa stres atau menghadapi rasa stres, yaitu dengan memiliki manajemen stres yang baik. Siswa perlu memiliki manajemen stres yang baik agar siswa mampu mengendalikan stress selama kondisi pandemi dan selama proses LFH.

Manajemen stres memiliki pengaruh terhadap kondisi mental seseorang. Sehingga terdapat relevansi dengan penelitian ini. Seseorang yang memiliki manajemen stres baik akan mampu memberikan strategi coping stres yang baik. Begitu pun sebaliknya, seseorang yang memiliki manajemen stres kurang baik, akan memiliki kecenderungan memberikan strategi coping yang kurang tepat. Sehingga akan mengalami stres yang berkepanjangan dan dampaknya sangat negatif bagi diri sendiri. 
Manajemen stres merupakan suatu tindakan untuk melakukan pengontrolan atau pengaturan stres, hal ini bertujuan untuk mengenal penyebab stress dan mengetahui teknikteknik mengelola stres, sehingga orang lebih baik dalam menguasai stres dalam kehidupan. Schafer (Rohim, 2016). Jadi, manajemen stres merupakan kemampuan seseorang untuk mengelola stres agar dapat dikendalikan dan terkontrol sehingga tidak menimbulkan efek berkepanjangan dan dapat merugikan diri sendiri. Berdasarkan hasil wawancara dan permasalahan yang telah diuraikan diatas, maka peneliti tertarik untuk melakukan penelitian mengenai manajemen stress siswa SMP Negeri 132 Jakarta di masa pandemi Covid-19. Hal ini untuk mengetahui gambaran bagaimana manajemen stres siswa terutama dalam kondisi pandemi ini, yang memiliki tantangan lebih dibanding kondisi pra pandemi. Oleh karena itu peran bimbingan konseling sangat dibutuhkan untuk membantu siswa mengentaskan permasalahan dengan meningkatkan kemampuan manajemen stres.

Bimbingan dan Konseling memiliki kewajiban mengembangkan dan mengusai dirinya. Sebagai gambaran lebih jelasnya tercantum dalam Bab II A tentang kualifikasi guru BK atau Konselor. Bagian 1.a menyebutkan "konselor wajib terus menerus berusaha mengembangkan dan menguasai dirinya. Ia wajib mengerti kekurangan-kekurangan dan prasangka-prasangka pada dirinya sendiri, yang dapat mempengaruhi hubungannya dengan orang lain dan mengakibatkan rendahnya mutu pelayanan profesional serta merugikan klien (Abkin, 2005). oleh karena itu penelitian ini dilakukan untuk menganalisis tingkat kemampuan manajemen stres pada siswa SMP Negeri 132 Jakarta, sehingga data hasil penelitian dapat dimanfaatkan oleh guru BK untuk memberikan layanan kepada siswa.

\section{Metode Penelitian}

Penelitian ini menggunakan metode deskriptif kuantitatif. Menurut (Sugiyono, 2018) penelitian kuantitatif merupakan penelitian yang berlandaskan pada pengumpulan data dengan menggunakan instrumen penelitian, dan analisis data bersifat kuantitatif. Demikian pula pada tahap kesimpulan pada umumnya disertai dengan grafik, gambar, tabel, dan lainnya. Sedangkan penelitian deskriptif merupakan penelitian yang bertujuan untuk mendeskripsikan suatu hal yang secara aktual (Irawan,2002). Penelitian ini dilakukan di SMP Negeri 132 Jakarta. Jumlah sampel dalam penelitian ini berjumlah 100 siswa. Teknik pemilihan sampel, peneliti menggunakan purposive simpel dengan alasan pertimbangan dan karakteristik yang telah ditentukan yaitu siswa yang mengelus stres terhadap pelaksanaan belajar daring (dalam jaringan). Pengumpulan data, peneliti menggunakan skala manajemen stres yang terdiri dari 5 aspek: (1) Manajemen waktu; (2) Membangun sikap optimis; (3) Mengatur aktivitas secara bijak; (4) Menghindari kebiasaan menunda; (5) Menjalin komunikasi yang harmonis. Skala manajemen stres yang digunakan sudah melalui uji validitas dan reabilitas sebesar 0,948 pada kategori sangat bagus untuk dijadikan instrumen penelitian. Selanjutnya analisis data penelitian menggunakan statistik deskriptif.

\section{Hasil dan Pembahasan}

Tingkat manajemen stres siswa SMP Negeri 132 Jakarta dihitung dengan cara mengumpulkan data serta dianalisis menggunakan teknik analisis yang sudah dijabarkan pada bab III yaitu dengan menggunakan kategorisasi. Adapun hasil distribusi frekuensi manajemen stres siswa SMP Negeri 132 Jakarta di masa pandemi Covid-19, disajikan dalam tabel berikut: 
Tabel 1: Distribusi Frekuensi dan Persentase Manajemen Stres Siswa SMP Negeri 132 Jakarta, Kelas VII Di Masa Pandemi Covid-19

\begin{tabular}{lllll}
\hline Norma/Kriteria Skor & Rentang Skor & Kategori & $\mathrm{F}$ & $\%$ \\
\hline $\mathbf{M}+\mathbf{I S D} \leq \mathbf{X}$ & $165 \leq \mathbf{X}$ & Tinggi & 8 & $16 \%$ \\
\hline $\mathbf{M}-\mathbf{I S D} \leq \mathbf{X}<+$ ISD & $149 \leq \mathrm{X}<165$ & Sedang & 36 & $72 \%$ \\
\hline $\mathbf{X}<\mathbf{M}$ - ISD & $\mathrm{X}<149$ & Rendah & 6 & $12 \%$ \\
\hline
\end{tabular}

Berdasarkan tabel 4.1 diketahui pada siswa kelas VII SMP Negeri 132 Jakarta terdapat 8 siswa yang memiliki manajemen stres sedang. Hal ini ditunjukkan dengan persentase mencapai $16 \%$. Selanjutnya, terdapat 36 siswa yang memiliki tingkat manajemen stres sedang, dengan persentase mencapai $72 \%$. Dan yang terakhir terdapat 6 siswa yang memiliki tingkat manajemen stress rendah, dengan persentase mencapai $12 \%$.

Tabel 2: Distribusi Frekuensi dan Persentase Manajemen Stres Siswa SMP Negeri 132 Jakarta, Kelas VIII Di Masa Pandemi Covid-19

\begin{tabular}{lllll}
\hline Norma/Kriteria Skor & Rentang Skor & Kategori & $\mathrm{F}$ & $\%$ \\
\hline $\mathbf{M}+\mathbf{I S D} \leq \mathbf{X}$ & $178 \leq \mathrm{X}$ & Tinggi & 9 & $18 \%$ \\
\hline $\mathbf{M}-\mathbf{I S D} \leq \mathbf{X}<+\mathbf{I S D}$ & $142 \leq \mathrm{X}<178$ & Sedang & 34 & $68 \%$ \\
\hline $\mathbf{X}<\mathbf{M}$ - ISD & $\mathrm{X}<142$ & Rendah & 7 & $14 \%$ \\
\hline
\end{tabular}

Hasil pengumpulan data dari siswa kelas VIII SMP Negeri 132 Jakarta terdapat 9 siswa yang memiliki manajemen stres tinggi. Hal ini ditunjukkan dengan persentase mencapai $18 \%$. Selanjutnya, terdapat 34 siswa yang memiliki tingkat manajemen stres sedang, dengan persentase mencapai 68\%. Dan yang terakhir terdapat 7 siswa yang memiliki tingkat manajemen stress rendah, dengan persentase mencapai $14 \%$.

Setelah melakukan penelitian pada siswa SMP Negeri 132 Jakarta kelas VII dan kelas VIII dengan jumlah total 100 responden/sampel menunjukkan hasil bahwa mayoritas siswa SMP Negeri 132 Jakarta memiliki tingkat manajemen stres yang sedang. Hal ini ditunjukkan dengan hasil persentase yang mencapai $72 \%$ atau 36 siswa untuk kelas VII dengan jumlah siswa 50 orang dan mencapai $68 \%$ atau 34 siswa untuk kelas VIII dengan jumlah siswa 50 orang. Sedangkan pada kategori rendah pada kelas VII terdapat $12 \%$ atau 6 siswa dan pada kelas VIII terdapat 14\% atau 7 siswa. Dan untuk kategori tinggi terdapat 16\% atau 8 siswa untuk kelas VII dan 18\% atau 9 siswa untuk kelas VIII.

Menurut (Robbins \& Judge, 2008), seseorang yang memiliki kemampuan mengelola stres dengan baik memiliki ciri-ciri diantaranya mampu memberikan respons yang positif ketika mendapat tekanan. Sebagai contoh ketika seseorang mendapatkan tuntutan pekerjaan yang berlebihan, bagi seseorang yang memiliki kemampuan mengelola stres rendah akan cenderung memberikan respons negatif, seperti stres, yang mengakibatkan terganggunya kondisi kesehatan fisik. Namun, sebaliknya seseorang yang memiliki kemampuan mengelola stres dengan baik, membawa dirinya serileks mungkin, serta akan memikirkan strategi atau cara agar pekerjaan tersebut terselesaikan tanpa mengakibatkan stres.

Hasil penelitian ini menunjukkan bahwa siswa yang berada pada kategori rendah memiliki kecenderungan untuk mengalami stres berat karena memiliki kemampuan manajemen stres yang kurang baik dalam dirinya. Sehingga jika dibiarkan dapat mengganggu aktivitas sehari-hari. Menurut (Robbins \& Judge, 2008) bahwa dampak stres dapat berpengaruh terhadap kondisi kesehatan fisik seperti sakit kepala, tekanan darah tinggi, serta dapat berpengaruh terhadap kondisi psikis seseorang, seperti mudah cemas, 
bahkan dapat menyebabkan depresi. Dalam hal ini, secara keseluruhan siswa SMK Muhammadiyah Sungailiat Bangka sudah mampu memiliki manajemen stres yang sedang. Dapat artikan sudah mampu mengelola stres cukup baik. Hal ini ditunjukkan dengan kemampuan berkomunikasi dengan lingkungan maupun teman sebaya serta kemampuan membangun sikap optimis yang memiliki persentase cukup baik. Sehingga ada kecenderungan untuk mampu berkatarsis dengan teman ketika mengalami stres.

Berdasarkan hasil penelitian diat menunjukkan bahwa tingkat manajemen stres siswa SMP Negeri 132 Jakarta di kelas VII maupun kelas VIII pada kategori Sedang, ini bermakna apabila pihak sekolah terutama guru BK tidak memberikan layanan bimbingan konseling yang tepat, maka kecenderungan siswa akan mengalami stres lebih besar. Oleh karena itu untuk meningkatkan manajemen stres pada siswa ada beberapa faktor yang harus diperhatikan. Menurut (Saputra, 2016:35) faktor yang mempengaruhi manajemen stres sebagai Sosial upaya mereduksi atau mengelola stres adalah dukungan sosial dan kepribadian. Kedua faktor itu lebih lanjut dijelaskan sebagai berikut: (1) dukungan sosial, (2) kepribadian, (3). Oleh karena itu pada musim pandemi covid-19, tidak menutup kemungkinan guru BK dalam memberikan layanan. Peran guru bimbingan dan konseling akan menjadi malaikat tak bersayap untuk membantu siswa. Data lengkap dari semua keluhan peserta didik dan orang tua akan menjadi modal bagi guru bimbingan dan konseling. Seorang guru bimbingan dan konseling yang kompeten harus mampu melaksanakan 3M yaitu mendengar, memahami dan merespons (Tim Penyusun, 2011). Guru BK mampu mendengar dengan baik yang terucap maupun tersirat, agar mampu memahami masalah konseli / siswa sehingga mampu memberikan respons agar konseli merasa nyaman dan diterima. Komunikasi efektif dengan siswa, orang tua, guru mata pelajaran dan pimpinan sekolah akan menjadi solusi di masa pandemi ini. Efektif bisa diterjemahkan suatu usaha yang dilakukan secara maksimal sesuai yang diharapkan, dapat pula di artikan suatu usaha yang tidak mengenal lelah sebelum harapan yang diinginkan tercapai (Kusumah, 2020). Pembahasan masalah siswa dengan tetap menjaga kerahasiaan menjadi poin penting. Kemampuan guru BK dalam layanan mediasi harus semakin dipupuk. Banyak cara yang bisa dilakukan untuk melatih diri agar mampu menjadi mediator yang bisa menjembatani antara siswa dan guru. Guru BK wajib bisa membaca situasi sehingga mampu menyampaikan kendala siswa ke guru tanpa ada kesalahpahaman atau terkesan menggurui, sehingga upaya guru dalam meningkatkan manajemen stres siswa di musim pandemi dapat terlaksanakan.

\section{Kesimpulan}

Berdasarkan hasil analisis data dan pembahasan yang telah diuraikan sebelumnya, maka dapat disimpulkan berdasarkan hasil penghitungan menggunakan rumus kategorisasi diperoleh hasil bahwa tingkat Manajemen stres siswa kelas VII secara keseluruhan berada pada kategori sedang dengan jumlah 36 siswa, atau $72 \%$. Selanjutnya untuk kategori tinggi terdapat 8 siswa atau 16\%. Dan kategori rendah hanya berjumlah 6 siswa atau 12\%. Sedangkan tingkat manajemen stres siswa kelas VIII secara keseluruhan berada pada kategori sedang dengan jumlah 34 siswa atau 68\%. Selanjutnya untuk kategori tinggi terdapat 9 siswa atau 18\%. Dan kategori rendah hanya berjumlah 7 siswa atau 14\%. Artinya kemampuan manajemen stres siswa SMP Negeri 132 Jakarta berada pada kategori sedang. 


\section{Daftar Pustaka}

Azwar, S. (2012). Penyusunan Skala Psikologi. Pustaka Belajar.

Baskara, B. (2020, April). Rangkaian Peristiwa Pertama Covid-19. Kompas.

Hurlock, E. B. (1980). Psikologi Perkembangan (R. M. Sijabat (ed.); kelima). Erlangga. Irawan, S. (2002). Metode Penelitian Sosial. Rosdakarya.

Fraenkel, J. R.,\& Wallen, N. E (2001). Educational Research: A Guide to the Process (2nd ed). New Jersey, N. J: Lawrence Erlbaum Association Inc.

Purwanto, A., Pramono, R., Asbari, M., Santoso, P. B., Wijayanti, L. M., Hyun, C. C., \& Putri, R. S. (2020). Studi Eksploratif Dampak Pandemi COVID-19 Terhadap Proses Pembelajaran Online di Sekolah Dasar. Education, Psychology and Counseling Journal, Volume 2(April), 2716-4446.

Rasmun. (2004). stres, koping, dan adaptasi (pertama). CV. Sagung Seto.

Robbins, S. P., \& Judge, T. A. (2008). Perilaku Organisasi (D. Sunardi (ed.); 12th ed.).

Salemba Empat.

Rohim, R. (2016). HUBUNGAN ANTARA SPIRITUALITAS DAN MANAJEMEN STRES PADA INDIVIDU PARUH BAYA.

Saputra, S. D. (2016). PENGARUH RELIGIUSITAS TERHADAP MANAJEMEN STRES PADA SISWA KELAS XII SMA NEGERI 1 KASIHAN. In IOSR Journal of

Economics and Finance (Vol. 3, Issue 1). https://doi.org/https://doi.org/10.3929/ethz-b000238666

Sarastika, P. (2014). Manajemen Pikiran untuk Mengatasi Stres Depresi Kemarahan \& Kecemasan (Rmomandhon MK (ed.)). Araska.

Segarahayu, R. D. (2014). Pengarub manajemen stres terbadap penurunan tingkat stres pada narapidana di lpw malang. 1-16. http://jurnalonline.um.ac.id/data/artikel/artikelDEB288149FBAA98C9CB27EB18035D95A.pdf

Siregar, S. (2015). Statistik Parametrik untuk Penelitian Kuantitatif. PT Bumi Aksara. Sugianto, D. (2020, June). Begini Dahsyatnya Efek Corona ke Ekonomi. Detik Finance. Sugiyono. (2018). Metode Penelitian Kuantitatif. Alfabeta.

Syah, R. H. (2020). Dampak Covid-19 pada Pendidikan di Indonesia: Sekolah, Keterampilan, dan Proses Pembelajaran. SALAM: Jurnal Sosial Dan Budaya Syar-I, 7(5). https://doi.org/10.15408/sjsbs.v7i5.15314

Wahyuningtiyas, E. P., Fasikhah, S. S., \& Amalia, S. (2019). Hubungan Manajemen Stres Dengan Perilaku Prokrastinasi Akademik Pada Mahasiswa Yang Sedang Menyusun Skripsi. Jurnal RAP (Riset Aktual Psikologi Universitas Negeri Padang), 10(1). https://doi.org/10.24036/rapun.v10i1.105006

Waluyo, M. (2013). psikologi industri (Y. Acitra (ed.)). indeks.

Wijayanti, N. (2013). Strategi Coping Menghadapi Stres Dalam Penyusunan Tugas Akbir Skripsi Pada Mahasiswa Program S1 Fakultas Ilmu Pendidikan. https:// core.ac.uk/download/pdf/33513483.pdf 